\title{
International spinal cord injury urodynamic basic data set (version 2.0)
}

\author{
Jürgen Pannek ${ }^{1}$ Michael Kennelly ${ }^{2} \cdot$ Thomas M. Kessler $^{3} \cdot$ Todd Linsenmeyer $^{4,5}$ - Jean-Jacques Wyndaele ${ }^{6}$. \\ Fin Biering-Sørensen ${ }^{7}$
}

Received: 30 July 2018 / Revised: 15 October 2018 / Accepted: 16 October 2018

(C) International Spinal Cord Society 2018

\begin{abstract}
Study design: Revision, review, and presentation of the International Spinal Cord Injury (SCI) Urodynamic Basic Data Set (version 2.0).

Objectives: Describe the revision and review and present the dataset.

Setting: International.

Methods: The first version of the dataset was revised according to new knowledge and suggestions. The review included International SCI Data Sets Committee, American Spinal Injury Association (ASIA) board, International Spinal Cord Society (ISCoS) executive and scientific committees, major organizations, and interested individuals. The dataset was also on ASIA and ISCoS websites. All replies were answered and appropriate adjustments made. Finally, the dataset was endorsed by ASIA board, and ISCoS executive and scientific committees.

Results: Among revisions are adoptions of new terminology by the International Continence Society. The variable "Detrusor function" has been divided into "Detrusor function during filling cystometry" and "Detrusor function during voiding". The response categories have been adjusted, deleting 'Not applicable' for the variables "Detrusor leak point pressure during filling cystometry", "Cystometric bladder capacity during filling cystometry" and "Urethral function during voiding". The cutoff-value for low bladder compliance has been modified from $10 \mathrm{~mL} / \mathrm{cm} \mathrm{H}_{2} \mathrm{O}$ to $20 \mathrm{~mL} / \mathrm{cm} \mathrm{H}_{2} \mathrm{O}$.

Conclusions: The International SCI Urodynamic Basic Data Set (version 2.0) with its complete syllabus is available from http://www.iscos.org.uk/international-sci-data-sets.
\end{abstract}

Electronic supplementary material The online version of this article (https://doi.org/10.1038/s41394-018-0133-0) contains supplementary material, which is available to authorized users.

$\checkmark$ Jürgen Pannek

juergen.pannek@paraplegie.ch

1 Neuro-Urology, Swiss Paraplegic Centre, Nottwil, Switzerland

2 Carolinas Rehabilitation, Carolinas Healthcare System, Charlotte, NC, USA

3 Neuro-Urology, Spinal Cord Injury Center and Research, Balgrist University Hospital, University of Zürich, Zürich, Switzerland

4 Urology Department, Kessler Institute for Rehabilitation, W. Orange, NJ, USA

5 Departments Surgery (Urology) and PM\&R, Rutgers New Jersey Medical School, Newark, NJ, USA

6 University Antwerp, Antwerp, Belgium

7 Clinic for Spinal Cord Injuries, Rigshospitalet, University of Copenhagen, Copenhagen, Denmark

\section{Introduction}

Collection of data during urodynamic studies is universal when individuals with spinal cord lesions are evaluated for their lower urinary tract function. However, the collection of these data has not been performed in a standardized way until the first version of the International Spinal Cord Injury (SCI) Urodynamic Basic Data Set was published in 2008 [1]. The purpose of this dataset was to standardize the collection and the reporting of a minimum amount of information from the urodynamic study in daily practice in accordance with the purpose and vision of the International SCI Data Sets [2]. Use of a standard format is essential to evaluate and compare results from various published studies, to evaluate urodynamic studies in a uniform manner and for combining data from multiple investigators and locations.

All International SCI Data Sets undergo periodic review to ensure continued relevance, acceptance and usage by the 
SCI clinical/research community. In addition, the International SCI Data Sets were reviewed for their relevance for pediatric SCI. The aim of this presentation is to describe the revision and review process, and present the final updated version of the International SCI Urodynamic Basic Data Set (Version 2.0).

\section{Methods}

The first version of the International SCI Urodynamic Basic Data Set was revised based on the recently published literature and suggestions received from the SCI community. The review included consultation with the International SCI Data Sets Committee, the American Spinal Injury Association (ASIA) board, the International Spinal Cord Society (ISCoS) executive and scientific committees, major related national and international organizations, and interested individuals who asked to be on a reviewer mailing list. In addition, the dataset was posted on ASIA and ISCoS websites for a month inviting everyone to submit comments.

All suggestions were evaluated and responded to by the Working Group (the authors) and adjustments were made if regarded as appropriate. When reviewing proposed revisions, the potential benefits of the proposal were weighed against the loss of continuity resulting from any revision. These changes, apart from minor corrections, are summarized below in the revised comments to the variables and in the data collection form in the Appendix.

After the revision and review the final International SCI Urodynamic Basic Data Set (Version 2.0) was endorsed by the ASIA board and the ISCoS executive and scientific committees and made freely available with the complete syllabus at http://www.iscos.org.uk/international-sci-data-sets.

\section{Results}

The order of the variables has been adjusted so that all variables measured during filling cystometry come before the variables measured during or after voiding. As the International Continence Society (ICS) has made an update on the terminology for adult neurogenic lower urinary tract dysfunction [3], the wording of the comments were adjusted according to the recent terminology for the following variables: 'Bladder sensation during filling cystometry", "Detrusor leak point pressure during filling cystometry", "Cystometric bladder capacity during filling cystometry", "Detrusor function during voiding" and variable "Urethral function during voiding". In addition, the definition for "low compliance bladder" was modified and the category
"Detrusor function" was subdivided into "Detrusor function during filling cystometry" and "Detrusor function during voiding".

Below the variables with the adjustments are given, and in the Appendix the complete data collection can be found.

\section{Bladder sensation during filling cystometry}

This variable documents the bladder sensation during filling cystometry. Although the bladder sensation is assessed during filling cystometry the assumption that it is sensation from the bladder alone, without urethral or pelvic components may be false [4]. The above terms are according to the ICS defined as:

Normal bladder sensation can be judged by three defined points noted during filling cystometry and evaluated in relation to the bladder volume at that moment and in relation to the patient's symptomatic complaints. First sensation of bladder filling is the feeling the patient has, during filling cystometry, when he/she first becomes aware of the bladder filling. First desire to void is defined as the feeling, during filling cystometry, that would lead the patient to pass urine at the next convenient moment, but voiding can be delayed if necessary. Strong desire to void this is defined, during filling cystometry, as a persistent desire to void without the fear of leakage [4].

Increased bladder sensation is defined as an early first sensation of bladder filling (or an early desire to void) and/ or an early strong desire to void, which occurs at low bladder volume and which persists. Reduced bladder sensation is defined as diminished sensation throughout bladder filling. Absent bladder sensation means that, during filling cystometry, the individual has no bladder sensation. Abnormal sensations mean awareness of sensation in the bladder, urethra or pelvis, described with words like "tingling," "burning," or "electric shock," in the setting of a clinically relevant neurologic disorder (eg, incomplete spinal cord lesion) [3]. Non-specific bladder awareness is defined as perception of bladder filling as abdominal fullness, vegetative symptoms, spasticity or other "non-bladder awareness," in the setting of a clinically relevant neurologic disorder (eg, incomplete spinal cord lesion) [3]. Unknown is used if the observation regarding bladder sensation during filing cystometry is not available. This includes children of $0-5$ years of age.

\section{Detrusor function during filling cystometry}

This variable documents the function of the detrusor during filling, i.e., the overactivity is determined during filling, while the acontractility or detrusor underactivity is determined during voiding. Normal detrusor function allows 
bladder filling with little or no change in pressure. No involuntary phasic contractions occur despite provocation. For a given detrusor contraction, the magnitude of the recorded pressure rise will depend on the degree of outlet resistance [4].

Neurogenic detrusor overactivity is an urodynamic observation in individuals with a neurological condition characterized by involuntary detrusor contractions during the filling phase, which may be spontaneous or provoked [4]. Unknown is used if the observation regarding detrusor function is not available.

\section{Maximum detrusor pressure during filling cystometry}

This variable documents the maximum detrusor pressure in $\mathrm{cm} \mathrm{H}_{2} \mathrm{O}$ during filling cystometry. Up to three digits without decimals may be used. Maximum detrusor pressure is defined as the highest detrusor pressure measured during filling cystometry. Unknown is used if the observation regarding maximum detrusor pressure during filling cystometry is not available. It should be used if circumstances arise during urodynamics, ie. autonomic dysreflexia that prohibits further urodynamic evaluation.

\section{Bladder compliance during filling cystometry}

Bladder compliance during filling cystometry describes the relationship between change in bladder volume and change in detrusor pressure. Compliance is calculated by dividing the volume change $(\Delta V)$ by the change in detrusor pressure $(\Delta p d e t)$ during that change in bladder volume $(C=\Delta V /$ $\Delta$ pdet), expressed in $\mathrm{mL} / \mathrm{cm} \mathrm{H}_{2} \mathrm{O}$ [4]. The International Continence Society recommends to calculate the bladder compliance using two standard points: 1) the detrusor pressure at the start on the bladder filling and the corresponding bladder volume (usually zero), and 2) the detrusor pressure (and corresponding bladder volume) at cystometric capacity or immediately before the start of any detrusor contraction that causes significant leakage (and therefore causes the bladder volume to decrease, affecting compliance calculation). Both points are measured excluding any detrusor contraction [4]. The bladder compliance during filling cystometry in individuals with spinal cord lesions is controversial regarding the level of cutoff point for normal and low [5]. The ICS defines low compliance as a compliance value lower than $20 \mathrm{~mL} / \mathrm{cm} \mathrm{H}_{2} \mathrm{O}$ [6]. This is also currently the most frequently used cutoff value in the field of neuro-urology $[7 ; 8]$. The exact value should be given. Unknown is used if the observation regarding bladder compliance during filling cystometry is not available.

\section{Detrusor leak point pressure during filling cystometry}

Detrusor Leak Point Pressure (DLPP) is defined as the lowest detrusor pressure at which urine leakage occurs in the absence of either a detrusor contraction or increased abdominal pressure [3]. This variable is reported in $\mathrm{cm} \mathrm{H}_{2} \mathrm{O}$ during filling cystometry. Up to three digits without decimals may be used.

Unknown is used if the observation regarding detrusor leak point pressure is not available. If circumstances arise during urodynamics, ie. autonomic dysreflexia that prohibits further urodynamic evaluation, then unknown should be used.

\section{Cystometric bladder capacity during filling cystometry}

This variable documents the cystometric bladder capacity in mililiters during filling cystometry. Up to four digits without decimals may be used. Cystometric bladder capacity during filling cystometry is the bladder volume at the end of the filling cystometrogram, when "permission to void" is usually given. The end point should be specified, for example, if filling is stopped when the patient has a normal desire to void. The cystometric capacity is the volume voided together with any residual urine. In the absence of sensation, the cystometric capacity is the volume at which the clinician decides to terminate filling. The reason(s) for terminating filling should be defined, e.g., high detrusor filling pressure, large infused volume, autonomic dysreflexia or pain. If there is uncontrollable voiding, it is the volume at which this begins. In the presence of sphincter incompetence, the cystometric capacity may be significantly increased by occlusion of the urethra e.g., by Foley catheter [4]. Unknown is used if the observation regarding cystometric bladder capacity during filling cystometry is not available. It should be used if circumstances arise during urodynamics, ie. autonomic dysreflexia that prohibits further urodynamic evaluation.

\section{Detrusor function during voiding}

This variable documents the function of the detrusor during voiding, i.e., determining detrusor underactivity, and acontractility during voiding. Therefore, it is applicable only in persons that can initiate voluntary voiding. In people that cannot initiate voluntary voiding, the variable "Initiated reflex bladder emptying", defined as an artificially elicited LUT reflex comprised of various maneuvers (exogenous stimuli) performed by the patient or the therapist, resulting in complete or incomplete bladder emptying, has been introduced [3]. Normal detrusor function allows bladder 
filling with little or no change in pressure. No involuntary phasic contractions occur despite provocation. Normal voiding is achieved by a voluntary initiated continuous detrusor contraction that leads to complete bladder emptying within a normal time span, and in the absence of obstruction. For a given detrusor contraction, the magnitude of the recorded pressure rise will depend on the degree of outlet resistance [4]. Neurogenic detrusor underactivity is defined as a contraction of reduced strength and/or duration, resulting in prolonged bladder emptying and/or a failure to achieve complete bladder emptying within a normal time span in the setting of a clinically relevant neurologic disorder [3]. Neurogenic acontractile detrusor is one that cannot be demonstrated to contract during urodynamic studies in the setting of a clinically relevant neurologic lesion [3]. Unknown is used if the observation regarding detrusor function is not available.

\section{Urethral function during voiding}

The coordination of voiding in individuals with a spinal cord lesion is a concern. This variable describes the function of the urethra during voiding. Normal urethra function during voiding is defined as a urethra that opens and is continuous relaxed to allow the bladder to be emptied at a normal pressure [4]. Detrusor sphincter dyssynergia is defined as detrusor contraction concurrent with an involuntary contraction of the urethral and/or periurethral striated muscle. Occasionally flow may be prevented altogether [4]. Non-relaxing urethral sphincter is characterized by a non-relaxing, obstructing urethral sphincter resulting in reduced urine flow [4] Delayed relaxation of the urethral sphincter is characterized by impaired and hindered relaxation of the sphincter during voiding attempt resulting in delay of urine flow [3]. Unknown is used if the observation regarding function during voiding is not available.

\section{Post void residual volume}

Post void residual is defined as the volume of urine left in the bladder at the end of micturition [4]. It is documented in mililiter. Up to four digits without decimals may be used. Not applicable should be used if the individual for example empties the bladder with a urostomy. Unknown is used if the observation regarding post void residual volume is not available.

\section{Discussion}

For individuals with SCI, video-urodynamics are the recommended gold-standard, and should be performed if possible. For standardized collection and reporting of radiologic findings during video-urodynamics, the International SCI Imaging Basic Data Set [9] should be used. If video-urodynamics are not available, filling cystometry and a pressure flow study (if applicable) should be performed. In addition, the data in this International SCI Urodynamic Basic Data Set will generally be used with the International SCI Core Data Set (Version 2.0) [10], which includes information on date of birth and injury, gender, the cause of spinal cord lesion, the neurologic status, and the International SCI Lower Urinary Tract Function Basic Data Set (Version 2.0) [11]. Another related International SCI Data Set is the International SCI Urinary Tract Infection Basic Data Set [12]. Lower urinary tract function is assessed as part of the International Standards to Assess Autonomic Function and the SCI Urodynamic Data Set is meant to be complimentary to these International Standards[13].

A spinal cord lesion may be traumatic or non-traumatic in etiology. All lesions to the spinal cord, conus medullaris, and cauda equina are included in the present context.

It is extremely important that data be collected in a uniform manner. For this reason, each variable and each response category within each variable has been defined to promote the collection and reporting of comparable minimal data.

Use of a standard format is essential for combining data from multiple investigators and locations. The SCI Urodynamic Data Set seems to be well suited for this purpose, as its first version has already been used in several studies [1417] and has been translated into Chinese [https://www. iscos.org.uk//international-sci-urodynamic-data-sets]. Various formats and coding schemes may be equally effective and could be used in individual studies or by agreement of the collaborating investigators.

The International SCI Urodynamic Basic Data Set (version 2.0) with its complete syllabus is available from http://www.iscos.org.uk/international-sci-data-sets.

Acknowledgements For the second version comments and suggestions were received from Susan Charlifue, Eva Widerström-Noga, Vanessa Noonan, and Ernst Scriba.

\section{Compliance with ethical standards}

Conflict of interest The authors declare that they have no conflict of interest.

\section{References}

1. Biering-Sørensen F, Craggs M, Kennelly M, Schick E, Wyndaele JJ. International urodynamic basic spinal cord injury data set. Spinal Cord. 2008;46:513-6.

2. Biering-Sørensen F, Charlifue S, DeVivo M, Noonan V, Post M, Stripling T, et al. International spinal cord injury data sets. Spinal Cord. 2006;44:530-4. 
3. Gajewski JB, Schurch B, Hamid R, Averbeck M, Sakakibara R, Agrò EF, et al. An International Continence Society (ICS) report on the terminology for adult neurogenic lower urinary tract dysfunction (ANLUTD). Neurourol Urodyn. 2018;37:1152-61. https://doi.org/10.1002/nau.23397

4. Abrams P, Cardozo L, Fall M, Griffiths D, Rosier P, Ulmsten U, et al. The Standardisation of Terminology of Lower Urinary Tract Function: Report from the Standardisation Sub-committee of the International Continence Society. Neurourol Urodyn. 2002;21:167-78.

5. Weld KJ, Graney MJ, Dmochowski RR. Differences in bladder compliance with time and associations of bladder management with compliance in spinal cord injured patients. J Urol. 2000;163:1228-33.

6. Stöhrer M, Goepel M, Kondo A, Kramer G, Madersbacher H, Millard R, et al. The standardization of terminology in neurogenic lower urinary tract dysfunction: with suggestions for diagnostic procedures. International Continence Society Standardization Committee. Neurourol Urodyn. 1999;18:139-58.

7. Hackler RH, Hall MK, Zampieri TA. Bladder hypocompliance in the spinal cord injury population. J Urol. 1989;141:1390-3.

8. Wyndaele JJ, Gammie A, Bruschini H, De Wachter S, Fry CH, Jabr RI, et al. Bladder compliance what does it represent: can we measure it, and is it clinically relevant? Neurourol Urodyn. 2011;30:714-22.

9. Biering-Sørensen F, Craggs M, Kennelly M, Schick E, Wyndaele J-J. International urinary tract imaging basic spinal cord injury data set. Spinal Cord. 2009;47:379-83.

10. Biering-Sørensen F, DeVivo MJ, Charlifue S, Chen Y, New PW, Noonan V, et al. International Spinal Cord Injury Core Data Set (version 2.0) - including standardization of reporting. Spinal Cord. 2017;55:759-64. https://doi.org/10.1038/sc.2017.59
11. Biering-Sørensen F, Kennelly M, Kessler TM, Linsenmeyer T, Pannek J, Vogel L, et al. International spinal cord injury lower urinary tract function basic data set (version 2.0). Spinal Cord Ser Cases. 2018;4:60.

12. Goetz LL, Cardenas DD, Kennelly M, Bonne Lee BS, Linsenmeyer $\mathrm{T}$, Moser $\mathrm{C}$, et al. International spinal cord injury urinary tract infection basic data set. Spinal Cord. 2013;51:700-4. https:// doi.org/10.1038/sc.2013.72

13. Krassioukov A, Biering-Sørensen F, Donovan W, Kennelly M, Kirshblum S, Krogh K, et al. International standards to document remaining autonomic function after spinal cord injury. J Spinal Cord Med. 2012;35:202-11. https://doi.org/10.1179/ 1079026812Z.00000000053

14. Liu N, Fougere R, Zhou MW, Nigro MK, Krassioukov AV. Autonomic dysreflexia severity during urodynamics and cystoscopy in individuals with spinal cord injury. Spinal Cord. 2013;51:863-7.

15. Hwang SI, Lee BS, Han ZA, Lee HJ, Han SH, Kim MO. Factors Related to the Occurrence of Urinary Tract Infection Following a Urodynamic Study in Patients With Spinal Cord Injury. Ann Rehabil Med. 2016;40:718-24.

16. Elmelund M, Klarskov N, Bagi P, Oturai PS, Biering-Sørensen F. Renal deterioration after spinal cord injury is associated with length of detrusor contractions during cystometry-A study with a median of 41 years follow-up. Neurourol Urodyn. 2017;36:1607-15. https://doi.org/10.1002/nau.23163

17. Hubscher $\mathrm{CH}$, Herrity AN, Williams CS, Montgomery LR, Willhite AM, Angeli CA, et al. Improvements in bladder, bowel and sexual outcomes following task-specific locomotor training in human spinal cord injury. PLoS ONE. 2018;13:e0190998. 